\title{
Vasoconstrictor response to cold in forestry workers: a prospective study
}

\author{
N OLSEN, S L NIELSEN \\ From the Departments of Clinical Physiology and Nuclear Medicine, Hvidovre Hospital, Rigshospitalet, and \\ Herlev Hospital, University of Copenhagen, Copenhagen, Denmark
}

ABSTRACT In a five year prospective study of the vasoconstrictor response to cold 37 forestry workers were investigated in 1978 and again in 1983. The subjects were classified into three groups: group A $(n=13)$ : no subjective finger symptoms in 1978 and continued sawing until 1983; group B $(n=12)$ : no symptoms in 1978 and stopped sawing before 1983 ; group $C(n=12)$ : vibration induced white finger (VWF) in 1978. A cold provocation test measuring the finger systolic blood pressure with a cuff and strain gauge technique during combined body cooling and finger cooling to $30^{\circ}, 15^{\circ}$, and $6^{\circ} \mathrm{C}$ was applied to all subjects at both investigations. In 1978 all groups had an increased cold response when compared with that of 20 non-exposed controls $(p<0.05)$, and the response was more exaggerated in group $C$ than in groups $A$ and $B(p<0.01)$. From 1978 to 1983 the vasoconstrictor response increased in group A $(p<0.05)$, was unchanged in group $B(p>$ $0 \cdot 10)$, and improved in group $C(p<0.05)$. The changes in cold response in groups $A$ and $C$ were significantly larger than the within day variation of the method $(p<0.01)$. The aggravation of group $\mathrm{A}$ indicates that a further five years use of anti-vibration chain saws induced an increased hyperreactivity in the vasoconstrictor mechanisms but led to subjective symptoms of VWF in only one subject. The improvement in group $C$ was in accordance with the improvements of subjective finger symptoms and was associated with a previous shift from saws without vibration damping devices to anti-vibration saws and with cessation of work. The results of group C indicate that VWF may improve or subjectively disappear if exposure to vibration is reduced or stopped. The cold provocation test was more sensitive than the Taylor-Pelmear stage assessments $(p<0.05)$. The test may be of guidance in evaluating preventive measures.

Vibration induced white finger (VWF) is a secondary form of Raynaud's phenomenon caused by vibrating hand tools. Several studies have reported a decrease in the prevalence and severity of VWF among forestry workers mainly due to the introduction of the anti-vibration chain saw in the late 1960 s and early $1970 \mathrm{~s}^{1-3}$ The investigations were performed as medical interviews, questionnaires, and visual evaluation of finger colours at cold provocation tests. ${ }^{1-3}$ The digital arterial response to cold, however, may be quantified by measurements of the change in finger systolic blood pressure after finger cooling. ${ }^{4}$ We have described a method for the routine evaluation of VWF based on this technique ${ }^{4}$ and it was applied to a group of forestry workers in $1978 .^{56}$ The purpose of the present study was to investigate the same subjects ${ }^{6}$ five years later.

Accepted 9 March 1987

\section{Subjects and methods}

In March 1978, 39 chain saw operators, being representative of 365 lumberjacks according to a completed questionnaire, were investigated and the results were compared with those of 20 non-exposed controls. ${ }^{6}$ At follow up 59 months later (in February 1983) one lumberjack had emigrated and another was having medical treatment for arterial hypertension. The longitudinal field study comprised the remaining 37 lumberjacks. A follow up of the controls was resisted by the employer. All subjects gave informed consent to the study, which was approved by the local ethical committee.

A medical interview showed that none had developed metabolic or vascular disorders other than VWF and none had received medical treatment. The subjects were classified into three groups on the basis of the medical interview: group A: no subjective finger 
Table 1 Characteristics of 37 lumberjacks. Group A: no subjective finger symptoms in 1978 and continued sawing until 1983; group B: no finger symptoms in 1978 and stopped sawing before 1983; group C:VWF in 1978. Values in 1978-denotes values in 1978 - and in 1983 or when work ceased. Values are given as numbers, dates, or median (range).

\begin{tabular}{|c|c|c|c|c|}
\hline & Year & Group A & Group B & Group C \\
\hline $\begin{array}{l}\text { No of men } \\
\text { Age } \\
\text { Exposure period (months) } \\
\text { Exposure period (years) } \\
\text { Median exposure time (h/day) } \\
\text { Use of gloves (No) } \\
\text { Use of A/V-saws only (No) } \\
\text { Shift from V-saws to A/V-saws (No) } \\
\text { Stopped using V-saws (date) } \\
\text { Use of V-saws (years) }\end{array}$ & $\begin{array}{l}1978 \\
1978-83 \\
1978 \\
1983 \\
1978- \\
1978-\end{array}$ & $\begin{array}{l}13 \\
41(18-63) \\
59(59-59)^{* *} \\
12(1-23) \\
17(5-28) \\
4-4 \\
10-13 \\
7 \\
6 \\
1972(1968-72) \\
10(4-17)\end{array}$ & $\begin{array}{l}12 \\
29(18-65) \\
27(5-52)^{*} \\
4(1-20) \\
6(2-21) \\
4-4 \\
9-10 \\
7 \\
5 \\
1972(1969-72) \\
9(3-14)\end{array}$ & $\begin{array}{l}12 \\
54(18-67) \\
59(18-59)^{* *} \\
15(2-20) \\
19(4-25)^{* *} \\
4-4 \\
6-10 \\
2 \\
9 \\
1973(1968-83) \\
8(1-15)\end{array}$ \\
\hline
\end{tabular}

*Significantly different from group A $(p<0.01) ;{ }^{* *}$ significantly different from group B $(p<0.05)$

$A / V$-saws and V-saws denote anti-vibration saws and chain saws without vibration damping devices respectively.

symptoms in 1978 and continued sawing until 1983; group B: no finger symptoms in 1978 and stopped sawing before 1983; group C: VWF in 1978. In group C eight subjects had continued sawing until 1983 and the other four had stopped sawing before 1983. VWF was defined as a history of cold provoked episodes of well demarcated blanching in one or more fingers with first appearance after occupational use of chain saws. ${ }^{7}$ Fewer subjective symptoms of VWF were defined as an impression of decreased number of episodes of blanched fingers or a lower temperature necessary to provoke the episodes. VWF had ceased if no attacks of VWF was noticed during the past two years. ${ }^{2}$ The Taylor-Pelmear stage assessments of the finger symptoms was performed ${ }^{7}$ : stage 0 : no symptoms; stage $0_{\mathrm{N}} / 0_{\mathrm{T}}$ : intermittent numbness or tingling; stage 1: blanching of one or more finger tips; stage 2: blanching of one or more fingers; stage 3: extensive blanching with frequent episodes in summer and winter, with definite interference with work; and stage 4: extensive blanching of all fingers in summer and winter, leading to change of occupation. One subject, who in 1978 had been classified as being in stage 2 showing a negative cold provocation test, denied any history of white finger in 1983. This lumberjack was classified as being in stage 0 at both investigations in the present study. The remaining 36 subjects confirmed their previous stages in 1978 at the interview in 1983. In 1978 five subjects had been in stage 2 and seven in stage 3 . The subjects were also asked about their age, smoking habits, use of gloves, exposure periods, and use of actual and previous types of chain saws. Table 1 gives the characteristics of the lumberjacks. The age of the controls was 37 (26-57), which differed significantly only from those of group $C(p<0.01)$. The number of smokers did not differ significantly between the four groups $(\mathrm{p}>0 \cdot 20)$. The tobacco consumption ( $\mathrm{g} /$ day) was significantly larger in group $C$ then in group $B$ and in controls in $1983(p \leqslant 0.05)$ but had not changed significantly within each of the three exposed groups $(\mathrm{p}>0 \cdot 10)$. Since 1979 only one subject in group C had continued to use chain saws without vibration damping devices (V-saws) (table 1).

The subjects were investigated in the supine position after at least 10 minutes at rest with the fingers at heart level and dressed in indoor clothing. Body cooling was performed by a cooling blanket perfused continuously with water at $8-12^{\circ} \mathrm{C}$, from 10 minutes before the measurements. The finger investigated in 1978 was reinvestigated in 1983. Finger systolic blood pressure (FSP) was measured by a strain gauge technique $^{8}$ after cooling the mid-phalanx during five minutes of ischaemia to $30^{\circ}, 15^{\circ}$, and $6^{\circ} \mathrm{C} .{ }^{56}$ The thumb served as a non-cooled reference. ${ }^{56}$ FSP at each of the lower two temperatures $(x)$ in the thermostated finger (th) was expressed in per cent of the pressure at $30^{\circ} \mathrm{C}$ in the same finger corrected for changes in arterial blood pressure during the investigation ${ }^{56}$ :

$$
\text { FSP\%(x) }=\frac{100 \cdot \mathrm{FSP}_{\text {th, } x}}{\text { FSP }_{\text {th, } 30}-\left(\mathrm{FSP}_{\text {ref, }} \mathbf{s 3}-\mathrm{FSP}_{\text {ref, sx }}\right.}
$$

where $\mathrm{FSP}_{\text {ref, }} \mathrm{sx}$ is the pressure measured simultaneously at the reference finger. A zero pressure at $15^{\circ}$ or $6^{\circ} \mathrm{C}$ verified arterial closure in the finger. ${ }^{4}$ Subjects with a zero pressure at $15^{\circ} \mathrm{C}$ were not tested at $6^{\circ} \mathrm{C}$ in 1978 but were in 1983 . The within day variation of the method was estimated from double determinations of FSP\% in lumberjacks in $1978 .^{6}$ The range of the outdoor temperature and of the room temperature was $-10^{\circ}$ to $5^{\circ} \mathrm{C}$ and $9-16^{\circ} \mathrm{C}$ in 1978 and $-10^{\circ}$ to $0^{\circ} \mathrm{C}$ and $10-17^{\circ} \mathrm{C}$ in 1983 .

Statistical evaluation was performed by nonparametric statistics with a significance limit of 0.05 (two sided). The difference in numerical values between related samples was tested with the Wilcoxon test or Pratt's test if the number of ties were $10 \%$ or more. The difference in the numerical values between independent samples was tested with the KruskallWallis test followed by the Mann-Whitney test. The 
Table 2 Results of the cold provocation test. Finger systolic blood pressure at $30^{\circ} \mathrm{C}\left(\mathrm{FSP} \mathrm{P}_{\text {th.30 }}\right)$ and at $15^{\circ}$ and $6^{\circ} \mathrm{C}$ in percentage of FSP $P_{\text {th, } 30}$ (FSP\%) in 20 controls and in 37 lumberjacks divided into three groups as follows: group A: no subjective finger symptoms in 1978 and continued sawing until 1983; group B: no finger symptoms in 1978 and stopped sawing before 1983; group $C: V W F$ in 1978. Values are given as median (range)

\begin{tabular}{|c|c|c|c|c|c|}
\hline & $\begin{array}{l}\text { Controls } \\
(n=20)\end{array}$ & $\begin{array}{l}\text { Group A } \\
(n=13)\end{array}$ & $\begin{array}{l}\text { Group B } \\
(n=12)\end{array}$ & $\begin{array}{l}\text { Group C } \\
(n=12)\end{array}$ & $\begin{array}{l}D D D \\
(n=19)\end{array}$ \\
\hline 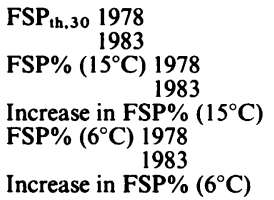 & $\begin{array}{r}110(80-135) \\
91(70-105) \\
83(60-100)\end{array}$ & $\begin{array}{l}110(85-145) \\
115(100-160) \\
83(0-100) \dagger \\
61(0-87)^{*} \\
-10(-76 \text { to } 57)+\ddagger \S \\
64(0-107)^{\mathrm{a} *} \\
42(0-97)^{\mathrm{a} *} \\
-15(-72 \text { to } 57)^{\mathrm{a}}+\S\end{array}$ & $\begin{array}{l}115(90-150) \\
123(100-150) \\
79(0-100) \dagger^{*} \\
76(0-92)^{*} \\
1(-67 \text { to } 28) \dagger \\
50(33-100)^{b *} \\
64(0-86)^{b *} \dagger \\
-1(-50 \text { to } 44)^{b}\end{array}$ & $\begin{array}{c}105(80-135) \\
125(80-200) \ddagger \\
0(0-82)^{*} \\
20(0-100)^{*} \\
15(0-94) \ddagger \S \\
0(0-0)^{\mathrm{c}} \\
0(0-53)^{\mathrm{d} *} \\
16(0-32)^{\mathrm{c}}\end{array}$ & $\begin{array}{l}0(-11 \text { to } 32) \\
4(0-20)^{e} \ddagger\end{array}$ \\
\hline
\end{tabular}

$\mathrm{a}: \mathrm{n}=12 ; \mathrm{b}: \mathrm{n}=11 ; \mathrm{c}: \mathrm{n}=2 ; \mathrm{d}: \mathrm{n}=8 ; \mathrm{e}: \mathrm{n}=13$.

*Significantly different from controls $(p<0.05)$.

†Significantly different from group $C(p<0.05)$.

† Significant difference within the group $(p \leqslant 0.05)$.

Significantly different from DDD ( $p<0.01)$

No other significant differences between the groups or within the group ( $p>0.05$ ).

$\mathrm{DDD}=$ Within day difference between double determinations of FSP\% in lumberjacks.

difference in nominal values between related samples and between independent samples was tested with the Sign test and with Fisher's test.

\section{Results}

Five of the 37 subjects had changes in their TaylorPelmear stages ${ }^{7}$ : group A: one subject had changed to stage $0_{\mathrm{N}} / 0_{\mathrm{T}}$ and one to stage 3; group $B$ : one subject had changed to stage 2; group C: two subjects had changed from stages 2 and 3 to stage 0 . Nine subjects $(75 \%)$ in group $\mathrm{C}$ had subjectively fewer symptoms of VWF in 1983 than in $1978(\mathrm{p}<0.01)$ and three had unchanged symptoms and FSP\%. Both subjects who had developed VWF had used only anti-vibration saws (A/V-saws) and both had an abnormal FSP\% in 1978 and a zero pressure in 1983. Both subjects with cessation of VWF had an increase in $\mathrm{FSP} \%\left(15^{\circ} \mathrm{C}\right)$ but still showed a closure pressure at $6^{\circ} \mathrm{C}$ in 1983 . One subject in group B, who changed to A/V-saw in 1972 and had cessation of VWF before 1978, had a closure at both investigations. Table 2 gives the results of the cold provocation test. The increase in $\mathrm{FSP}_{\text {th.30 }}$ of group $\mathrm{C}$ (table 2) may indicate that the increase in FSP $\%\left(15^{\circ} \mathrm{C}\right)$ of group $\mathrm{C}$ was underestimated. The increase in FSP\% $\left(15^{\circ} \mathrm{C}\right)$ was $58(25-94)$ in four subjects in group $\mathrm{C}$ who had stopped sawing before 1983 , and three (0-57) in eight subjects in group $C$ who had continued sawing until $1983(\mathrm{p}=0.02)$. The increase in $\mathrm{FSP} \%\left(15^{\circ} \mathrm{C}\right)$ was $14(0-94)$ in nine subjects in group $\mathrm{C}$ who had shifted from $\mathrm{V}$-saws to $\mathrm{A} / \mathrm{V}$-saws including three ex-sawyers $(p=0.05)$. The nine subjects with fewer subjective symptoms of VWF in 1983 showed an increase in FSP\% $\left(15^{\circ} \mathrm{C}\right)$ of $25(0-94)$ $(p=0.01)$ and included eight subjects who either had stopped sawing or had changed from V-saws to A-V- saws and one subject who had only changed to using gloves after 1978 .

Compared with the classification by means of fewer subjective finger symptoms in group $C(n=9)$ the Taylor-Pelmear stage assessments showed improvements in two subjects $(p<0.05)$, whereas FSP $\%\left(15^{\circ} \mathrm{C}\right)$ was increased in eight subjects. ${ }^{7}$ Six of seven subjects with unchanged stage and fewer subjective symptoms of VWF had an increase in FSP\% $\left(15^{\circ} \mathrm{C}\right)(\mathrm{p}<0.05)$

\section{Discussion}

In the present study all groups exposed to vibration showed an exaggerated vasoconstrictor response to cold at both investigations when compared with nonexposed controls, with the most exaggerated response in the group with VWF in 1978. At follow up in 1983 the vasoconstrictor response had increased in group A, was unchanged in group B, and had improved in group $\mathrm{C}$. The changes in the vasoconstrictor response in groups $\mathrm{A}$ and $\mathrm{C}$ were significantly larger than the within day variation of FSP $\%$. The cold provocation test was found to be more sensitive than the TaylorPelmear stage assessments ${ }^{7}$ in evaluating changes in VWF.

The aggravation in the cold response in group $\mathrm{A}$ after another five years' use of $\mathrm{A} / \mathrm{V}$-saws indicates that the $\mathrm{A} / \mathrm{V}$-saw induces damage to the vasoconstrictor mechanisms. This may lead to development of VWF as observed in two of 25 subjects $(8 \%)$. The possible harmful effect of $\mathrm{A} / \mathrm{V}$-saws has been investigated in other studies. ${ }^{3910}$ By means of medical interviews, Riddle and Taylor found that three of 18 lumberjacks $(17 \%)$ had VWF after five years' use of A/V-saws. ${ }^{9}$ Futatsuka and Ueno 
reported that the prevalence of VWF in 1980 was $1.6 \%$ among 185 Japanese lumberjacks who started sawing in 1972-3. ${ }^{3}$ Pyykkö et al noted that only three new forestry workers had been disabled by VWF since 1972 in their follow up materials of 217 men in $1980 .^{10}$ Thus only a few new cases of VWF caused by $\mathrm{A} / \mathrm{V}$-saws have been reported since the saw was introduced. The use of A/V-saws, however, may induce a small deterioration of the vasoconstrictor response to cold as was found in group A of the present study. The unchanged cold response in group $\mathbf{B}$ of the present study may be explained by the exposure period of only 27 months' use of A/V-saws since 1978 followed by a 32 months cessation of sawing.

The improved cold response in group $\mathrm{C}$ was in accordance with the improvements of subjective finger symptoms and could be explained partly by a shift from V-saws to A/V-saws and partly by stopping the use of saws. The results indicate that VWF may improve or subjectively recover if the exposure to vibration is reduced or stopped. This is in contrast with the findings of Agate in 1949, ${ }^{11}$ which suggested that VWF had a tendency to progress after exposure to vibration had ceased. In 1970, however, Stewart and Goda reported that, five years after cessation of exposure, $30 \%$ of the subjects no longer experienced attacks of VWF. ${ }^{12}$ A longitudinal study of Finnish forestry workers reported a decrease in the prevalence of VWF from $40 \%$ in 1972 to $5 \%$ in 1983 mainly due to the introduction of $\mathrm{A} / \mathrm{V}$-saws. ${ }^{2} 1013 \mathrm{~A}$ cold provocation test evaluating the colour of the fingers was performed annually on lumberjacks initially suffering from VWF. ${ }^{10} \mathrm{~A}$ gradual decline in the percentage of positive tests was observed in agreement with the decreasing prevalence of VWF. ${ }^{10}$ A longitudinal study of English lumberjacks showed improvements of VWF in ex-sawyers and in active sawyers who had changed from using $\mathrm{V}$-saws to $\mathrm{A} / \mathrm{V}$-saws. ${ }^{19} \mathrm{~A}$ prospective study of VWF among Japanese forestry workers showed a decrease in prevalence from $28 \%$ in 1973 to $17 \%$ in 1980 in active workers and a $50 \%$ decrease in prevalence in subjects who had not been exposed for more than 12 years. ${ }^{3}$ Thus most prospective studies show an improvement in VWF after a shift from V-saws to $\mathrm{A} / \mathrm{V}$-saws and after cessation of exposure as we have found here. ${ }^{1-39101213}$

The subjective symptoms of VWF are assumed to be reversible ${ }^{3910}$ and not progressive as previously suggested. ${ }^{11}$ VWF may exist, however, despite subjective recovery, as seen in two subjects of the present study, and may be of such severity that the subjective symptoms also remain or even progress after cessation of exposure. ${ }^{914}$ Previously only a single prospective study evaluated changes in VWF by means of a qualitative and more objective test than the medical interview and questionnaires. ${ }^{10}$ In the present study the vasoconstrictor response to cold was quantitatively measured by an objective method $^{45}$ that was more sensitive than the Taylor-Pelmear stage assessments ${ }^{7}$ in detecting small changes of VWF.

The investigation was supported by the Fund of Occupational Environment, the Jubilee Fund of the Nordic Coinsurance Company, and the University of Copenhagen.

Requests for reprints to: Niels Olsen, MD, Department of Clinical Physiology and Nuclear Medicine, Rigshospitalet, Blegdamsvej 9, DK-2100 Copenhagen Ø, Denmark.

\section{References}

1 Taylor W, Pelmear PL, Person JCG. A longitudinal study of Raynaud's phenomenon in chain saw operators. In: Taylor W, Pelmear PL, eds. Vibration white finger in industry. London: Academic Press, 1975:15-20.

2 Pyykkö I, Sairanen E, Korhonen O, Färkkilä M, Hyvärinen J. A decrease in the prevalence and severity of vibration-induced white fingers among lumberjacks in Finland. Scand $J$ Work Environ Health 1978;4:246-54.

3 Futatsuka M, Ueno T. A follow-up study of vibration-induced white finger due to chain-saw operation. Scand $J$ Work Environ Health 1986;12:304-6.

4 Nielsen SL, Lassen NA. Measurement of digital blood pressure after local cooling. $J$ Appl Physiol 1977;43:907-10.

5 Olsen N, Nielsen SL. Diagnosis of Raynaud's phenomenon in quarrymen's traumatic vasospastic disease. Scand J Work Environ Health 1979;5:249-56.

6 Olsen N, Nielsen SL, Voss P. Cold response of digital arteries in chain saw operators. Br J Ind Med 1982;39:82-8.

7 Taylor W, Pelmear PL. Vibration white finger in industry. London: Academic Press, 1975:xvii-xxii.

8 Hirai M, Nielsen SL, Lassen NA. Blood pressure measurements of all five fingers by strain gauge plethysmography. Scand $J$ Clin Lab Invest 1976;36:627-32.

9 Riddle HFV, Taylor W. Vibration-induced white finger among chain sawyers nine years after the introduction of antivibration measures. In: Brammer AJ, Taylor W, eds. Vibration effects on the hand and arm in industry. New York: John Wiley \& Sons, 1982:169-72.

10 Pyykkö I, Korhonen OS, Färkkilä MA, Starck JP, Aatola SA A longitudinal study of the vibration syndrome in Finnish forestry workers. In: Brammer AJ, Taylor W, eds. Vibration effects on the hand and arm in industry. New York: John Wiley \& Sons, 1982:157-67.

11 Agate JN. An outbreak of cases of Raynaud's phenomenon of occupational origin. Br J Ind Med 1949;6:144-63.

12 Stewart AM, Goda DF. Vibration syndrome. $\mathrm{Br} J$ Ind Med 1970;27:19-27.

13 Pyykkö I, Korhonen O, Färkkilä M, Starck J, Aatola S, Jäntti V. Vibration syndrome among Finnish forest workers, a followup from 1972 to 1983. Scand J Work Environ Health 1986;12:307-12.

14 Taylor W, Brammer AJ. Vibration effects on the hand and arm in industry: an introduction and review. In: Brammer AJ, Taylor $\mathrm{W}$, eds. Vibration effects on the hand and arm in industry. New York: John Wiley \& Sons, 1982:1-12. 